\title{
AC 2007-1811: DEVELOPING A CENTER FOR APPLIED RESEARCH AND TECHNOLOGY TRANSFER (CART, INC.) AT BLUEFIELD STATE COLLEGE
}

Bruce Mutter, Bluefield State College

Frank Hart, Bluefield State College 


\title{
Developing a Center for Applied Research and Technology Transfer (CART, Inc.) at Bluefield State College
}

\begin{abstract}
The paper updates the continuing development of the Center for Applied Research and Technology (CART, Inc.), at Bluefield State College (BSC), as a vehicle for entrepreneurial success. It discusses our Applied Research Assistant Program (ARAP) to provide teams of engineering technology students for our School of Engineering Technology and Computer Science (SETCS) with in-house internship experience and the School with a source of increased funding through CART, the operation of our own Course Management System (CMS) as a feebased self-sustaining business operation, our ongoing applied research projects for industry and agencies, our partnerships with other colleges, universities, industry, and government, and the operation of the shop CART store.
\end{abstract}

The vision of CART is to become a highly respected resource for innovative engineering and merging technologies in the discovery of applied research and design of applications that drive our economic viability, solve industrial problems, and strengthen homeland security and national defense.

Our specific mission is to produce moderate financial returns by providing efficient and effective research contracting, program development, and revenue generation for the BSC School of Engineering Technology and Computer Science. CART, Inc. will focus on innovation through applied research, transferring technologies to markets, continuing education, and raising funds that will enhance the overall competitiveness of Bluefield State College.

CART was created to enhance the competitive position of Bluefield State College for applied research opportunities in the current environment for research and development; promote the general economic development of the region; expedite and simplify the acquisition and utilization of research contracts; improve technology transfer; and link applied scientific research and technological advancements to economic development of the State of West Virginia. CART is a non-profit, non-stock corporation under the general corporation laws of the state organized exclusively for educational and scientific purposes within the meaning of section 501(c) [26 U.S.C. $§ 501(c)$ of the Internal Revenue Code of 1986, as amended, to foster and support applied research at the Bluefield State College School for Engineering Technology \& Computer Science and to provide evaluation, development, patenting, management and marketing for the inventions and diverse service capabilities of its students, faculty, and staff. CART operations are audited.

\section{Introduction}

CART, Inc. completes its first two years of operation with much value added to the School of Engineering Technology and Computer Science. Cutting edge technology surfaces on most of the projects; our faculty and students absorb this technology and the mentoring associated with it. The School and the College are winners. As exemplified by our participation in the 2005 DARPA Grand Challenge and the 2007 Urban Challenge, Team CART is part of an ambitious "field test intended to accelerate research and development in autonomous ground vehicles that 
will help save American lives on the battlefield." CART's challenge, then, is to "bring together individuals and organizations from industry, the R\&D community, government, the armed services," students, and faculty in the pursuit of meeting the technological challenge. This paper highlights the projects and activities happening through the Center. Continuous improvement needs nurturing to cause desired CART activities.

(CART) is up and running well. In the first two years of operation, we have continued to develop new applied research projects and technology services to better represent the School of Engineering Technology and Computer Science and Bluefield State College. Keeping

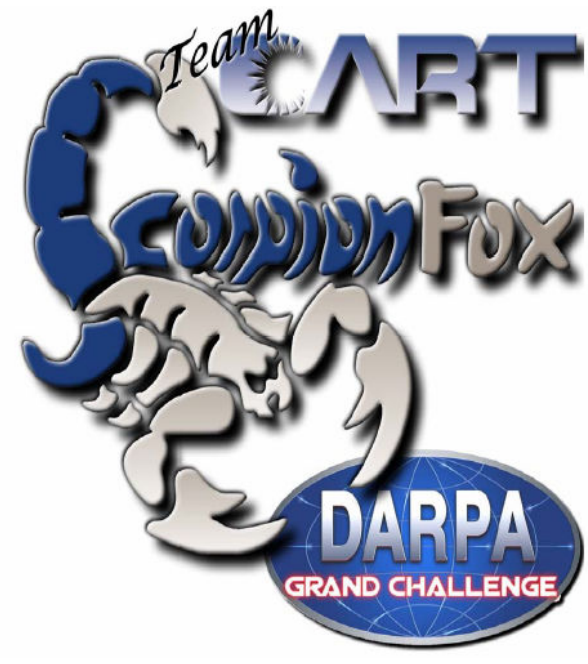
CART's vision and mission in mind, we worked diligently to meet the goals of our ambitious business plan. We have stayed within our project budgets without expense to the School or the College and teamed with the CART Board of Directors, our industrial partners, students and faculty to enhance both CART's effectiveness and impact. Financially, we covered our own expenses while strengthening the foundation for future growth even during these initial years of operation. The mechanisms required for creating a non-profit corporation within our School included the presence of an energetic, positive-minded, and supportive Dean, a cooperative administration, an understanding College board of governors, critically supportive industrial partners and advisory boards, and a general willingness to accept the risks and seek the rewards of entrepreneurship.

\section{DARPA Grand Challenge}

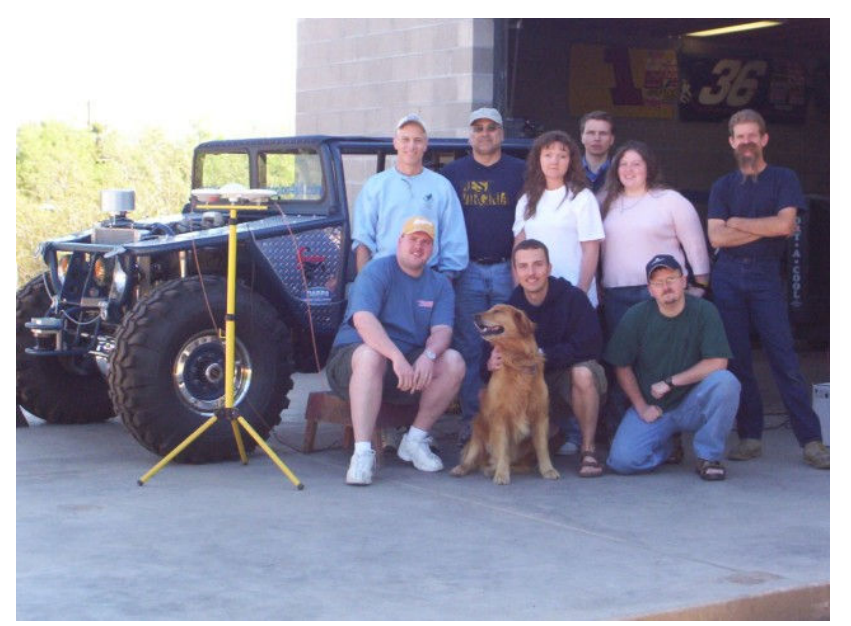

Entering the 2005 DARPA Grand Challenge was a bold initiative and our continued competitive participation challenges us to elevate our efforts and performance in every sense of the word. "The Challenge was held on 8 October 2005 in the desert Southwest. The team that develops an autonomous ground vehicle that finishes the designated route most quickly within 10 hours will receive $\$ 2$ million. The route will be no more than 175 miles over desert terrain featuring natural and manmade obstacles. The exact route will not be revealed until two hours before the event begins." This original announcement of the 2005 event on 8 June 2004 brought more than 800 interested entities to the Participant's Conference in Anaheim, CA on 14 August 2004. By 11 February 2005, at least 225 teams had filed entrance applications to DARPA, and of those 195 teams submitted the required demonstration video to complete their application. DARPA then trimmed the list to 118 teams selected for Site Visits and approximately 90 teams complied with the requirement. We invited the DARPA team to the Tucson Raceway Park in Arizona near our 
primary business partner, Preferred Chassis Fabrication, Inc., for a review of Team CART's vehicle in and again for a follow up visit later that month. We were an alternate semi-finalist for the National Qualifying Event and prepared for another Site Visit to occur during the week of 15-19 August 2005. We were eventually eliminated when the short list of 20 teams remained in the Challenge.

CART is preparing for another "Grand Challenge." We will enter the Defense Applied Research Projects Agency (DARPA) 2007 Urban Challenge. The Department of Defense-sponsored, "DARPA Urban Challenge," will feature autonomous ground vehicles executing simulated military supply missions safely and effectively in a mock urban area.

The 2007 DARPA Urban Challenge will take place in a yet-to-be disclosed urban setting, adding another dimension to the event. We are certainly looking forward to this new event. In the past, we have lacked the financial resources of many DARPA teams, but we have still been able to combine ingenuity and creativity to more than hold our own with the best industrial and academic organizations in the Grand Challenge. Additionally, the competition is an inspiring 'real world' applied research experience for faculty and students and helps them visualize the limitless potential for their future careers in engineering technology.

Our other successes with BSC student teams consisting of engineering technology and computer science students, working under the direction of Professor Robert Riggins have developed projects that yield concepts and data that can be used in this year's DARPA "Urban" Challenge. This time around, our Elise Fox is built around the Lotus platform by a team composed of College faculty, research associates, local industry engineers, students and alumni, and consultant expertise from the automotive and image processing communities.

DARPA will award prizes for the top three autonomous ground vehicles that compete in a final event where they must safely complete a 60-mile urban course in fewer than six hours. To succeed, vehicles must autonomously obey traffic laws while merging into moving traffic, navigating traffic circles, negotiating busy intersections, and avoiding obstacles.

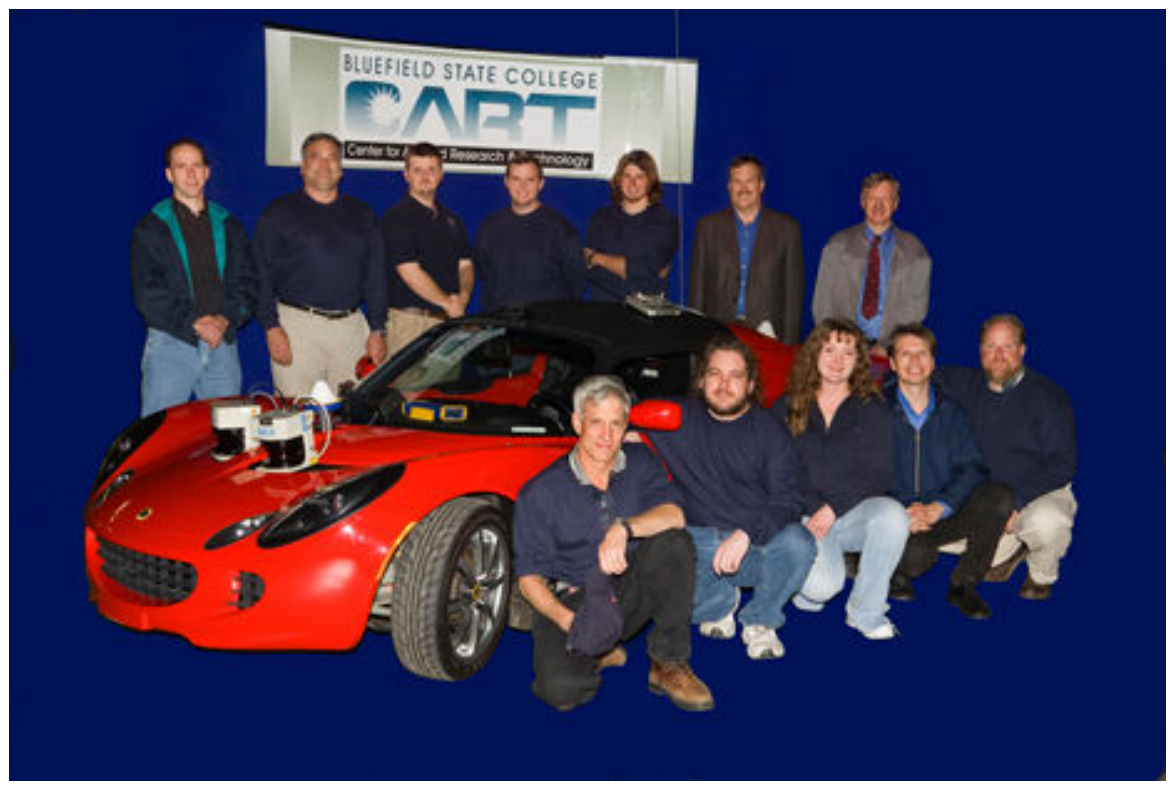




\section{CART CMS}

"Putting you before the Course" has become our motto for the CART Course Management System (CMS) since the 2004-05 year. The CMS reached a "user milestone," in February 2005 by topping its first 1000 class registrations. Located on the CART website at www.cartlink.org, CMS has now topped 3000 registrations from a multi-state area with its online course offerings and has generated over \$200,000 for CART, Inc.

\section{CART Inc. CMS}

\section{November 2006}

\section{Direct Financial Benefits and Costs}

- $\quad$ CART, Inc. has invested, and (-\$38,794.93) to develop CMS since 09/20/01.

- Since official inception in fall 2004: CART CMS fees earned total \$236,667.00.

- Since official inception in fall 2004 through 30 June 2007 - BSC expenses are $(\mathbf{- \$ 1 4 8 , 1 4 4 . 0 0 )}$.

- $\quad$ This provided a residual CART CMS fee total through December 2006 of $\mathbf{\$ 8 8 , 5 2 3 . 0 0}$.

\section{$\underline{\text { Some Indirect Financial Benefits and Costs }}$}

Since Spring 2003, 3901 students x 3.25 avg. credit hours/12 credit hours per semester = 1,057 FTE

1,057 FTE x $\$ 2,000.00$ per student in tuition, books, fees, gross revenues to $\mathrm{BSC}=\mathbf{\$ 2 , \mathbf { 1 1 4 , 0 0 0 . 0 0 }}$

1,057 FTE x (-30) mi./day commute x 17 days = 539,070 miles @ 0.445 per mile $=\$ 239,886.00$ savings for students

1,057 FTE x 3 extra work hours/week x $\$ 5.35$ hour x 17 weeks $=\$ 288,403$ increased earnings for students

\section{$\underline{\text { Risk Reduction Benefits and Liability Costs }}$}

Since inception, there are no fines, penalties, remediation, containment, legal fees, injury, and economic loss to the College, property misuse or damage associated with the operation of CART CMS. BSC does not purchase software, operate any server, or fund any marketing effort in connection with our CMS. BSC bears no upfront costs, pays no faculty development, and bears no specific responsibility regarding CMS. BSC Faculty using CMS generally create, prepare, author, save, present and manage their own courses. Materials are saved on Faculty computers and CMS supports excellent teaching. BSC students evaluate CMS coursework using BSC-designed survey instruments blind to instructor.

\section{$\underline{\text { Several Less Tangible Benefits and Costs }}$}

CART CMS is the delivery platform for COSC 490 - Cyber-infrastructure (Virginia Bioinformatics Institute). CART, Inc. and CMS are thought by many to be models for other institutions. CART, Inc. and CMS were cited as School wide strengths by TAC-ABET; we are in the College catalog. CART, Inc. is an award winning organization; CMS press example: "55 Good Things about WV"-State Journal. 


\section{$\underline{\text { Bottom Line }}$}

CART CMS Thesis: The line between what it means to be online and offline is long since blurred and will shortly disappear; for example, the inclusion of extremely low cost VOIP and net meetings, prevalent broadband access, and new faculty comfortable in the CMS environment, among many racing developments, will simply mean that "virtual College" equals College.

As one example in our CART CMS enabled course in ENGR 315 Engineering Economics we used the NPW of the CMS as an example online:

NET PRESENT WORTH ANALYSIS:

$$
\begin{aligned}
& \text { GIVEN: } \begin{array}{l}
\text { HURDLE RATE (OMB), } i=10 \%, P_{1}=\$ 38,794^{93}, P_{2}=\$ 88,523 . \\
n=7 \text { YRS, ESTIMATED REVENUE LESS EXPENSES }=A=\$ 100,000 / Y R
\end{array} \\
& \text { NPW }=\$ 38,794^{93}+\$ 88,523^{00}+\$ 100,000(P / A, 10 \%, 7)=\$ 614,157.93 \\
& A W=\$ 684^{\circ}
\end{aligned}
$$

The strengths of this system continue to be its simplicity and capacity for continual onsite improvement; faculty can utilize CMS without needing to become a programmer. Through the CART CMS, course materials, assignments, and information can be edited easily and promptly. CMS class registrations have grown at a near-exponential rate over the past few years. During its trial period of the spring 2004 Semester, CMS accommodated 105 registrations, and in the fall 2004 Semester, 192 CMS-based course registrations occurred. That number more than doubled during the spring 2005 Semester, with 459 registrations. Since June 2004, more than 300,000 separate user accounts have visited www.cartlink.org and the CART CMS website. Through the enhanced course assessment capabilities it provides, CMS also augments the individual faculty member's ability to target particular aspects of instruction and course work, making refinements that are needed to increase the efficiency and value of the course. Contacts and subsequent discussions with several different partner schools over the past two years have built a foundation for future growth in both the quantity and quality of web-delivered courses and programs through the CART CMS.

\section{CART ARAP}

The CART Applied Research Assistantship Program (ARAP) is a program that promises to create opportunities for meaningful interaction among our School's industrial partners and its students and faculty. The funded activities that have taken place over the past two years have been primarily architectural engineering technology led projects where our students used their CAD skills to make design drawings for E.T. Boggess, Architects, Inc., the Upperclassman II, the West Virginia Citizen's Conservation Corps (WVCCC), and a private residence. The students who worked on the WVCCC project presented their duplex cabin and bathhouse designs for the Twin Branch Recreation Area in Davy, West Virginia on Undergraduate Research Day at the State Capitol this February. These projects provide increased opportunities for paid 
scholarships in applied research: Projects in Engineering Technology credit, where approved, further interaction with school faculty, serve industry at low-cost with skilled interns on a temporary basis, lead to full-time employment in local firms, build confidence and resume' strength for students working in their fields of study, and further secure our partnerships with industry as a viable source of talent.

\section{IGVC}

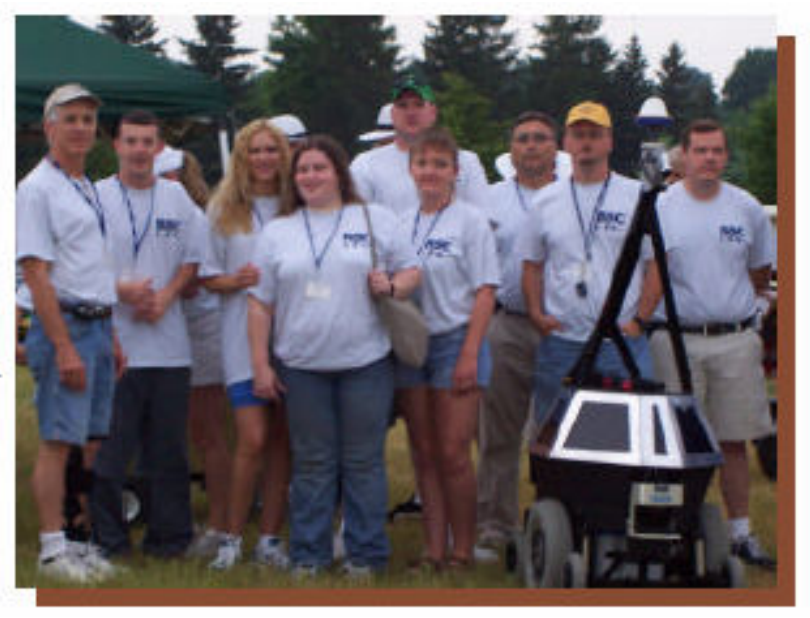

Preparation for the Intelligent Ground Vehicle Competition (IGVC) has become an annual highlight with increased expectations for the team from "Bluefield State University." For The $13^{\text {th }}$ and $14^{\text {th }}$ annual IGVC, CART provided support that included funding for the ARAP student team leader's dedicated research, GPS and navigational equipment purchases, the vehicle's drive platform, travel support, and funding for faculty research presentations related to the project. Students have gone on to NASA internships, graduate schools, and leadership in industrial robotics.

\section{CART Website}

Our website, www.cartlink.org experienced growth in both quality of service and meaningful visitor traffic over the past two years. We expanded our server capacity from a hosting unit to a dedicated server in September of 2004 to handle the increased number of visitors associated with interest in our applied research and technology projects, primarily related to DARPA, and the number of online courses offered through our online CMS. We increased our duplicate server's secure hard drive space 160 times from 500MB to $80 \mathrm{G}$, along with faster processing speeds and memory access, and greater automation and control. We have also automated the site with content management functions that allows content to be edited directly from the web. This permits the webmaster and others designated by password to enliven the site with new content and design features that will cause visitors to return for updated and useful information on a continually enhanced site. Responding to the need for continual improvement in serving our clients, the CART CMS system has also undergone two different version updates during the year from the CART CMS 2.3 through 2.4 and the recently released 2.5 that have resulted in improved evaluations of its quality. We are currently in the process of updating the server again and negotiating contracts for continual improvement to the site as a full enterprise solution complete with store, shopping cart, donor services, etc. 


\section{NJRII Appalachian Transportation Institute}

CART continues to serve the Nick J. Rahall

Appalachian Transportation Institute as the partner school campus coordinator for Bluefield State College. CART received a contract for more than Appalachian Transportation Institute $\$ 44,000$ through an agreement with the Marshall University Research Corporation on behalf of the Rahall Appalachian Transportation Institute (RTI).

The contract underwrites BSC-CART's costs related to providing campus coordination services for the Rahall Appalachian Transportation Institute. The Institute was established at Marshall University through a \$12 million grant funded by the U.S. Department of Transportation's Research and Special Program Administration as a University Transportation Center (UTC). RTI is one of 33 UTC's funded by the Department of Transportation and includes BSC among its three collaborative institutions of higher education.

Among CART's duties is the coordination of all activities related to the program at BSC, acting as a liaison between the Rahall Transportation Institute and its staff at Marshall and other collaborative institutions, and representing RTI at various public and private meetings.

\section{Et al}

CART has started to receive significant financial contributions from friends of the School. Supports include the Ethel N. Bowen Foundation, the George M. Cruise Foundation, the Resource Management Group, and others. We have continued to receive important equipment and service donations from our industrial partners including Preferred Chassis Fabrication, Inc., Cummins Diesel, Fugro Chance, PEMCO, Textron Systems, re $^{2}$ Inc., and King Tire, among others. Our involvement in the DARPA Grand Challenge, Urban Challenge, Virginia Bioinformatics Institute, continued success in the IGVC, serving industry through increased access to online courses, and the presence of a the center as a 501(c)3 dedicated to applied research and technology, has led to increased involvement with corporations, foundations, and individual friends that want to contribute to fulfilling our mission.

\section{Finances}

We noted at the beginning of this paper that FY 2004-2005 was our first year of operation. Starting with a zero baseline, CART generated $\$ 126,808$ in revenue during our first year without encumbering any debt, \$302,159 in work under contract for FY 2005-2006, and is poised to have a breakout year in new business. We continue to achieve our mission goals while maintaining self-sufficiency and developing new business.

Cognizant of concerns related to any start-up business, CART's accounting has been scrupulously entered into efficient, web-based software with access to records available by secure password to its Board of Director's and other appropriate concerns upon request and approval of its Board. CART has completed its first two Form 990 filings as required and 
complied with independent audits associated with Bluefield State College. We will adopt further suggestions offered by the College and our independent accountants as we seek to improve, grow, and comply with all required regulations. We contracted services from an independent accounting firm approved by our Board of Directors during our second year.

\section{Conclusions}

These are some highlights of projects, programs, and activities taking place at CART, Inc. These projects can be generally divided into applied research, technology services/support, and technology transfer outreach/products. We have mentioned activities from all three areas that defined the Center for Applied Research and Technology, Inc., increased growth and revenue, engaged new business partners and helped support the School of Engineering Technology and Computer Science and Bluefield State College. All of the above, we believe, have contributed to

a challenging but successful two years. We are proud of CART's success, and we are pleased to have been part of our School's continued excellence.

\section{CART}

- Enhances the competitive position of Bluefield State College for applied research opportunities in the current environment for research and development.

- Promotes the general economic development of the region by bringing together in one location the School of Engineering Technology and its industrial partners.

- Expedites and simplifies the acquisition and execution of research contracts.

- Improves technology transfer created from in-house synergies to the marketplace.

- Links applied scientific research and technological advancements to economic development of the State of West Virginia.

\section{REFERENCES}

CART Website: www.cartlink.org. 